DOI: $10.1515 /$ pts-2016-0020

\title{
INFLUENCE OF VOLTAGE DIPS ON THE OPERATION OF BRUSHLESS EXCITER SYSTEM OF SYNCHRONOUS MACHINES
}

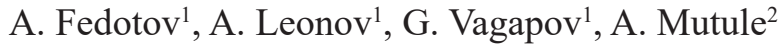 \\ ${ }^{1}$ Kazan State Powering Engineering University \\ 51 Krasnoselskaya Str., Kazan, RUSSIA \\ ${ }^{2}$ Institute of Physical Energetics, 21 Aizkraukles Str., Riga, LV-1006, LATVIA
}

\begin{abstract}
This paper presents a mathematical model with continuous variables for brushless exciter system of synchronous machines, containing the thyristor elements. Discrete Laplace transform is used for transition from a mathematical model of a system with variable structure in continuous variables to equation finite difference with permanent structure. Then inverse transition is made to a mathematical model in continuous variables with permanent structure.
\end{abstract}

Keywords: discrete transformation, exciter system, mathematical model, semiconductor thyristor, synchronous motor.

\section{INTRODUCTION}

This paper covers some issues of the development of a mathematical model of the synchronous machine in continuous variables taking into account the work of thyristor elements in exciter and ensuring adequate representation of electromagnetic processes based on the methods of converting the system from variable structure to permanent structure presented in various applications to electromechanical systems in [3]-[9].

Usually modern synchronous machines (SMs) are equipped with brushless exciter systems. They can be generators, as well as motors providing operation of respective technological mechanisms in the industrial plants of petrochemical complex, steel industry, in the system of thermal power plants for own needs. Short faults in distribution electrical networks of $110-220 \mathrm{kV}$ cause voltage dips on sections 6-10 kV of distribution switchgear of substations, to which SMs are connected [1] in the distribution grids of 110-220 kV. Exciter system of SMs is powered through transformers from the same sections, which reduces their ability to the field forcing and it can lead to loss of synchronism and disconnection by the relay protection from the grid. It is necessary to have the appropriate mathematical model in order to assess stability reserve of SM depending on the depth of voltage dips. The problem of the exciter system includes thyristor elements: controlled (static exciter) and uncontrolled (rotating exciter) thyristors, conditional on variable structure of differential 
equations, describe electromagnetic transient processes in SM [2]. In this case, any criteria estimation of stability reserve SM does not apply during short interruption of power supply (SIPS).

\section{MATERIALS AND METHODS}

\subsection{Mathematical Model of SM with Variable Structure}

A circuit diagram of the exciter system of SM is shown in Fig. 1, where VD1 the controlled rectifier pre exciter, VD2 - the uncontrolled rectifier of exciter, located on the rotor of SM; resistance R1, R2, R3 and thyristors T1, T2 provide field discharge in emergency modes of SM. The switch $Q$ is used to protect the SM and delivers its connection to the electricity grid.

The following assumptions are accepted for developing the mathematical model: the original equations of SM base on Park-Gorev model [10] with equivalenting damper contours of one winding longitudinal axis and one winding in the transverse axis, axis $d$ outstrips axis $q$.

Assembled on the three-phase bridge configuration thyristors of managed converter are considered to be ideal and they operate in the native mode. Native mode is mode with alternate conduction of two and three thyristors. Angle $\alpha$ of natural opening of thyristors is calculated from zero of corresponding phase EMF. Generally accepted notation [10] is saved in equations of synchronous machine. "Step" system of coordinates is used taking into account the work of thyristors. Thyristors of both converters are considered operational simultaneously (simultaneous opening of appropriate thyristors), taking into account that angle $\alpha_{0}$ of natural opening of thyristors depends on the phase of the EMF of grid $0.4 \mathrm{kV}$. The superscript " $\mathrm{g}$ " in the notation is used for parameters of exciter. Park-Gorev equation for SM will have the form:

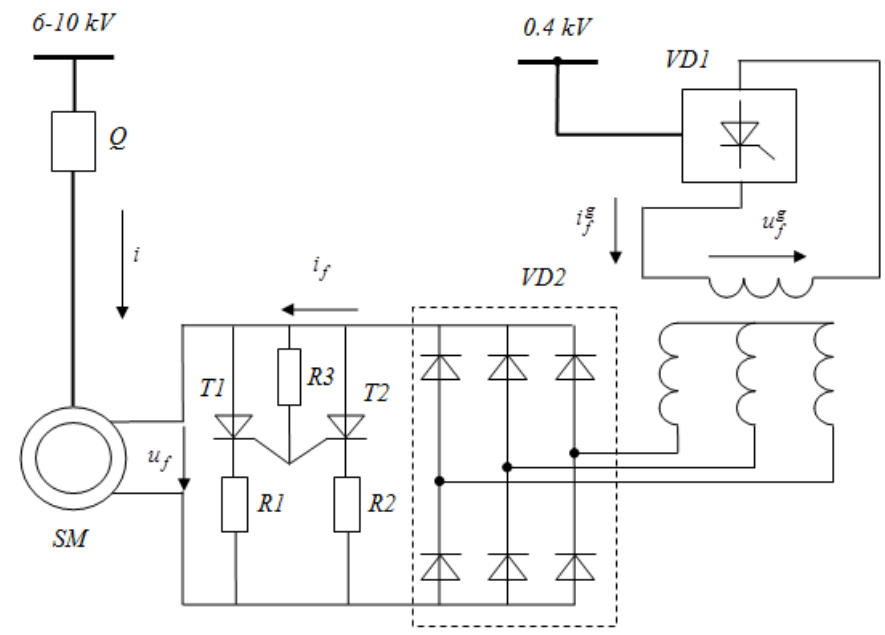

Fig. 1. Schematic diagram of the brushless exciter synchronous machine. 


$$
\left.\begin{array}{l}
-u_{d}=r i_{d}+\frac{d \Psi_{d}}{d \theta_{c}}+\omega \Psi_{q}, \quad \Psi_{d}=x_{d} i_{d}+x_{a d} i_{f}+x_{a d} i_{1 d}, \\
-u_{q}=r i_{q}+\frac{d \Psi_{q}}{d \theta_{c}}-\omega \Psi_{d}, \quad \Psi_{q}=x_{q} i_{q}+x_{a q} i_{1 q}, \\
u_{f}=r_{f} i_{f}+\frac{d \Psi_{f}}{d \theta_{c}}, \quad \Psi_{f}=x_{a d} i_{d}+x_{f} i_{f}+x_{a d} i_{1 d}, \\
0=r_{1 d} i_{1 d}+\frac{d \Psi_{1 d}}{d \theta_{c}}, \quad \Psi_{1 d}=x_{a d} i_{d}+x_{a d} i_{f}+x_{1 d} i_{1 d}, \\
0=r_{1 q} i_{1 q}+\frac{d \Psi_{1 q}}{d \theta_{c}}, \quad \Psi_{1 q}=x_{a q} i_{q}+x_{1 q} i_{1 q} .
\end{array}\right\}
$$

Differential equation exciter will have the form:

$$
\begin{aligned}
& -u_{d}^{g}=r^{g} i_{d}^{g}+\frac{d \Psi_{d}^{g}}{d \theta_{c}}+\omega \Psi_{q}^{g}, \quad \Psi_{d}^{g}=x_{d}^{g} i_{d}^{g}+x_{a d}^{g} i_{f}^{g}+x_{a d}^{g} i_{1 d}^{g}, \\
& -u_{q}^{g}=r^{g} i_{q}^{g}+\frac{d \Psi_{q}^{g}}{d \theta_{c}}-\omega \Psi_{d}^{g}, \quad \Psi_{q}^{g}=x_{q}^{g} i_{q}^{g}+x_{a q}^{g} i_{1 q}^{g}, \\
& u_{f}^{g}=r_{f}^{g} i_{f}^{g}+\frac{d \Psi_{f}^{g}}{d \theta_{c}}, \quad \Psi_{f}^{g}=x_{a d}^{g} i_{d}^{g}+x_{f}^{g} i_{f}^{g}+x_{a d}^{g} i_{1 d}^{g}, \\
& 0=r_{1 d}^{g} i_{1 d}^{g}+\frac{d \Psi_{1 d}^{g}}{d \theta_{c}}, \quad \Psi_{1 d}^{g}=x_{a d}^{g} i_{d}^{g}+x_{a d}^{g} i_{f}^{g}+x_{1 d}^{g} i_{1 d}^{g}, \\
& 0=r_{1 d}^{g} i_{1 d}^{g}+\frac{d \Psi_{1 d}^{g}}{d \theta_{c}}, \quad \Psi_{1 q}^{g}=x_{a q}^{g} i_{q}^{g}+x_{1 q}^{g} i_{1 q}^{g} .
\end{aligned}
$$

We write the equation of the relation between the excitation winding and exciter SM. For this equation of voltage balance for the excitation circuit of synchronous motor at the side of the exciter, local transformation on the m-recurrence interval is used. We consider one recurrence interval converter, including switching interval. The following voltage balance equation is valid in the stepping coordinate system, associated with switching thyristors, inside the recurrence interval converter within the length of phase commutation $\gamma$.

$$
-\sqrt{3} u_{d}^{g(m)} \sin \left(\theta^{(m)}-\pi / 3\right)+\sqrt{3} u_{q}^{g(m)} \cos \left(\theta^{(m)}-\pi / 3\right)=u_{f}^{(m)} .
$$

It will be equation considering the first two systems of equations (2) and the third equation of (1). 


$$
\begin{aligned}
& \frac{d}{d \theta}\left[\psi_{f}^{(m)}-\sqrt{3} \psi_{d}^{g(m)} \sin \left(\theta^{(m)}-\pi / 3\right)+\sqrt{3} \psi_{q}^{g(m)} \cos \left(\theta^{(m)}-\pi / 3\right)\right]= \\
& =\sqrt{3} r^{g}\left[i_{d}^{g(m)} \sin \left(\theta^{(m)}-\pi / 3\right)-i_{q}^{g(m)} \cos \left(\theta^{(m)}-\pi / 3\right)\right]-r_{f} i_{f}^{(m)} .
\end{aligned}
$$

The following relations link currents with each other

$$
\left.\begin{array}{l}
i_{d}^{g(m)}=(-2 / \sqrt{3})\left[i_{f}^{(m)} \sin \left(\theta^{(m)}-\pi / 3\right)+i_{\gamma}^{(m)} \sin \left(\theta^{(m)}+\pi / 3\right)\right], \\
i_{q}^{g(m)}=(2 / \sqrt{3})\left[i_{f}^{(m)} \cos \left(\theta^{(m)}-\pi / 3\right)+i_{\gamma}^{(m)} \cos \left(\theta^{(m)}+\pi / 3\right)\right], \\
\theta^{(m)} \in\left[\alpha_{0}^{(m)} ; \quad \alpha_{0}^{(m)}+\gamma_{0}^{(m)}\right] ; \\
i_{d}^{g(m)}=(-2 / \sqrt{3}) i_{f}^{(m)} \sin \left(\theta^{(m)}-\pi / 3\right), \\
i_{q}^{g(m)}=(2 / \sqrt{3}) i_{f}^{(m)} \cos \left(\theta^{(m)}-\pi / 3\right), \\
\theta^{(m)} \in\left[\alpha_{0}^{(m)}+\gamma_{0}^{(m)} ; \quad \alpha_{0}^{(m)}+\pi / 3\right] .
\end{array}\right\}
$$

\section{Wherein}

$$
i_{\gamma}^{(m)}\left(\alpha_{0}^{(m)}\right)=i_{f}^{(m)}\left(\alpha_{0}^{(m)}\right), \quad i_{\gamma}^{(m)}\left(\alpha_{0}^{(m)}+\gamma_{0}^{(m)}\right)=0
$$

where $\alpha_{0}$ - the angle of control of converter VD2 (Fig. 1).

The following equation is also true in the switching interval obtained based on balance voltage in the switching circuit:

$$
\sqrt{3} u_{d}^{g(m)} \sin \left(\theta^{(m)}+\pi / 3\right)-\sqrt{3} u_{q}^{g(m)} \cos \left(\theta^{(m)}+\pi / 3\right)=0
$$

It takes the following form after substituting voltage from (3)

$$
\begin{aligned}
& \frac{d}{d \theta}\left[\sqrt{3} \psi_{d}^{g(m)} \sin \left(\theta^{(m)}+\pi / 3\right)-\sqrt{3} \psi_{q}^{g(m)} \cos \left(\theta^{(m)}+\pi / 3\right)\right]= \\
& =-\sqrt{3} r^{g}\left[i_{d}^{g(m)} \sin \left(\theta^{(m)}+\pi / 3\right)-i_{q}^{g(m)} \cos \left(\theta^{(m)}+\pi / 3\right)\right] .
\end{aligned}
$$

We introduce the following notation for the flux linkage:

$$
\begin{aligned}
& \psi_{f g}^{(m)}=x_{a d} i_{d}^{(m)}+\left[x_{f}+x_{d}^{g}+x_{q}^{g}-\left(x_{d}^{g}-x_{q}^{g}\right) \cos 2\left(\theta^{(m)}-\pi / 3\right)\right] i_{f}^{(m)}- \\
& -\sqrt{3} x_{a d}^{g} \sin \left(\theta^{(m)}-\pi / 3\right) i_{f}^{g(m)}-\sqrt{3} x_{a d}^{g} \sin \left(\theta^{(m)}-\pi / 3\right) i_{1 d}^{g(m)}+ \\
& +\sqrt{3} x_{a q}^{g} \cos \left(\theta^{(m)}-\pi / 3\right) i_{1 q}^{g(m)}-\left[\frac{x_{d}^{g}+x_{q}^{g}}{2}+\left(x_{d}^{g}-x_{q}^{g}\right) \cos 2 \theta^{(m)}\right] i_{\gamma}^{g(m)}
\end{aligned}
$$




$$
\begin{aligned}
\psi_{f}^{g(m)}= & -\frac{2}{\sqrt{3}} x_{a d}^{g} \sin \left(\theta^{(m)}-\pi / 3\right) i_{f}^{(m)}+x_{f}^{g} i_{f}^{g(m)}+x_{a d}^{g} i_{1 d}^{g(m)}-\frac{2}{\sqrt{3}} x_{a d}^{g} \sin \left(\theta^{(m)}+\pi / 3\right) i_{\gamma}^{(m)} \\
\psi_{f \gamma}^{(m)}= & {\left[\frac{x_{d}^{g}+x_{q}^{g}}{2}+\left(x_{d}^{g}-x_{q}^{g}\right) \cos 2 \theta^{(m)}\right] i_{f}^{(m)}+\sqrt{3} x_{a d}^{g} \sin \left(\theta^{(m)}+\pi / 3\right) i_{f}^{g(m)}-} \\
& -\sqrt{3} x_{a d}^{g} \sin \left(\theta^{(m)}+\pi / 3\right) i_{1 d}^{g(m)}-\sqrt{3} x_{a q}^{g} \cos \left(\theta^{(m)}+\pi / 3\right) i_{1 q}^{g(m)}- \\
& -\left[x_{d}^{g}+x_{q}^{g}-\left(x_{d}^{g}-x_{q}^{g}\right) \cos 2\left(\theta^{(m)}+\pi / 3\right)\right] i_{\gamma}^{(m)} .
\end{aligned}
$$

The obtained expressions allow writing differential equation concerning the flux linkage using (5) and (6):

$$
\begin{aligned}
& \frac{d \psi_{d}^{(m)}}{d \theta_{c}}=r i_{d}^{(m)} \quad \omega \psi_{q}^{(m)} u_{d}^{(m)} ; \\
& \frac{d \psi_{q}^{(m)}}{d \theta_{c}}=r i_{q}^{(m)}+\omega \psi_{d}^{(m)} u_{q}^{(m)} ; \\
& \frac{d \psi_{f g}^{(m)}}{d \theta_{c}}=\left(r_{f}+2 r_{g}\right) i_{f}^{(m)}+r_{g} i_{\gamma}^{(m)}, \\
& \frac{d \psi_{f \gamma}^{(m)}}{d \theta_{c}}=r_{g}^{(m)} i_{f}^{(m)}+2 r_{g} i_{\gamma}^{(m)}, \\
& \frac{d \psi_{1 d}^{(m)}}{d \theta_{c}}=r_{1 d} i_{1 d}^{(m)} ; \\
& \frac{d \psi_{1 q}^{(m)}}{d \theta_{c}}=r_{1 q} i_{1 q}^{(m)} ; \\
& \left.\frac{d \psi_{f}^{g(m)}}{d \theta_{c}}=r_{f}^{g} i_{f}^{g(m)}+\gamma_{f}^{(m)} ; \alpha_{0}^{(m)}+h^{(m)}\right] \\
& \frac{d \psi_{1 d}^{g(m)}}{d \theta_{c}}=r_{1 d}^{g} i_{1 d}^{g(m)} ; \\
& \frac{d \psi_{1 q}^{g(m)}}{d \theta_{c}}=r_{1 q}^{g} i_{1 q}^{g(m)} .
\end{aligned}
$$

The voltage $u_{f}^{g}$ of exciter is not determined in (7). The voltages $u_{d}$ and $u_{q}$ are determined after writing the equations of electric grid external to SM.

\subsection{The Dynamic Characteristics of the External Converter Pre-exciter}

Voltage balance equation will be the following for single-phase thyristor converter VD1 (Fig. 1), in the transition process [2], [7], [9] in the range of its repeat- 
ability

$$
u_{f}^{g}=u_{c}(\theta)-r_{c} i_{f}^{g}-x_{c} \frac{d i_{f}^{g}}{d \theta}-K(\theta)\left(r_{c} i_{\gamma}^{g}-x_{c} \frac{d i_{\gamma}^{g}}{d \theta}\right),
$$

where $u_{c}$-the mains voltage, power supply converter pre-exciter;

$r_{c}$ and $x_{c}$-active and inductive resistance of power supply converter pre-exciter, respectively;

$i_{\gamma}^{g}$-switching current, wherein $i_{\gamma}^{g}(\alpha)=-2 i_{f}^{g}(\alpha) i_{\gamma}^{g}(\alpha+\gamma)=0$;

$K(\theta)=1(\theta-\alpha)-1(\theta-\alpha-\gamma)-$ a key step function;

$1(\theta-\alpha), \quad 1(\theta-\alpha-\gamma)-$ a single function.

According to [11], local integral transformation (LIT) function $f(\theta)$ on $\mathrm{T}$ - th interval discretization $\left[\begin{array}{ll}\alpha & \alpha+h^{(m)}\end{array}\right]$ is determined in the following way

$$
F(m)=\frac{1}{h^{(m)}} \int_{\alpha+h^{(m)}}^{\alpha} f(\theta) d \theta
$$

According to (8), LIT collates the continuous function of its discrete average value at a predetermined interval.

If in the grid of $0.4 \mathrm{kV}$ the supply voltage of converter does not change in the transitional process on the side of a high voltage, it can be taken as $u_{c}(\theta)=E_{c} \sin \theta$. Applying LIT for (7) on the $m$-th interval of borders $\left[\begin{array}{cc}\alpha & \alpha+\pi\end{array}\right]$, we obtain

$$
U_{f s}^{g(m)}=\frac{2 E_{c}}{\pi} \cos \alpha-r_{c} I_{f_{s}}^{g(m)}-\left(\frac{2 x_{c}}{\pi}-\frac{r_{c} \gamma}{\pi}\right) i_{f l}^{g(m)}-\frac{x_{c}}{\pi} \Delta i_{f l}^{g(m)} .
$$

In (9) subscript " $s$ " means the average value of a variable interval of discretization, subscript " $l$ " applies to the value of the variable at the starting point of the interval.

It can be written using a linear approximation of the current

$$
i_{f l}^{g(m)} \approx i_{f s}^{g(m)}-\frac{1}{2} \Delta i_{f l}^{g(m)}
$$

The dynamic external characteristic of converter in discrete variables is obtained after substituting (10) in (9):

$$
U_{f}^{g(m)}=\frac{2 E_{c}}{\pi} \cos \alpha-\left(r_{c}+\frac{2 x_{c}}{\pi}-\frac{r_{c} \gamma}{\pi}\right) I_{f_{s}}^{g(m)}-\frac{r_{c} \gamma}{2 \pi} \Delta i_{f l}^{g(m)} .
$$

Active resistance $r_{c}$ is much less compared with inductive impedance of $\tilde{o}_{\tilde{n}}$ converter transformer of pre-exciter connected to $0.4 \mathrm{kV}$. We neglect its influence in (11). Then it conclusively turns into 


$$
U_{f}^{g(m)}=\frac{2 E_{c}}{\pi} \cos \alpha-\frac{2 x_{c}}{\pi} I_{f s}^{g(m)} .
$$

Corresponding to the equivalent, the equation can be written in the instantaneous values of variables

$$
u_{f}^{g}=\frac{2 E_{c}}{\pi} \cos \alpha-\frac{2 x_{c}}{\pi} i_{f}^{g} .
$$

Control angle $\alpha$ is measured from zero phase EMF on the side of $0.4 \mathrm{kV}$ in (12).

Appropriate voltage dip arises on the side of $0.4 \mathrm{kV}$ during voltage dips on the side of $6-10 \mathrm{kV}$. In this case, supply voltage of excitation winding of exciter invariable should not be considered. It is possible to take [10], according to which supply voltage of converter of pre-exciter is expressed by the following equation

$$
u_{c}(\theta)=U_{c p} \sin \left(\theta-\psi_{p}\right)+\left(U_{c 0}+U_{c p} \sin \psi_{p}\right) e^{-\chi \theta}
$$

where $\operatorname{ctg} \psi_{p}=\chi=1 / \omega T_{p}, T_{p}$ - time constant in the transitional process, $U_{c 0}-$ initial voltage of dip; $U_{c p}$ - the final voltage of $\operatorname{dip}($ at $\theta \rightarrow \infty$ ).

It is necessary to determine the limit of integration interval for the use of LIT. Since they are combined with recurrence intervals of converter, their duration is unequal. The second term of (13) influences the duration of each interval.

Part of the voltage waveform is below abscissa axis even at $\theta>0$ under ordinary proportions of grid settings:

$$
\begin{aligned}
& U_{c s}^{(m)}=\frac{1}{2 \pi} \int_{\alpha_{1}+2 \pi m-\psi_{p}}^{\alpha_{2}+2 \pi m-\psi_{p}} u_{c}(\theta) d \theta-\frac{1}{2 \pi} \int_{\alpha_{2}+2 \pi m-\psi_{p}}^{\alpha_{1}+2 \pi(m+1)-\psi_{p}} u_{c}(\theta) d \theta= \\
& =\frac{1}{\pi} U_{c p}\left[\cos \left(\alpha_{1}\right)-\cos \left(\alpha_{2}\right)\right]+\frac{1}{2 \pi \chi} U_{a}\left[e^{-\chi \alpha_{1}\left(1+e^{-\chi 2 \pi}\right)}-2 e^{-\chi \alpha_{2}}\right] e^{-\chi\left(2 \pi m-\psi_{p}\right)} .
\end{aligned}
$$

Equation (14) defines the law of change of the voltage to the exciter winding in the case of disturbance on the grid side. It contains the angle values $\alpha_{1}$ and $\alpha_{2}$, determining the interval of operating time cathode group of thyristors of converter VD1 (Fig. 1). The necessary changes should be performed to exclude these angles from (14). Attenuation of the aperiodic component will not be taken into account in (13):

$$
u_{c}=A \sin (\theta-\alpha)+B
$$

Then the beginning of positive half of waves of the rectified voltage corresponds to the implementation of conditions 


$$
\sin \alpha=B / A .
$$

Apparently, process is periodic with period $2 \pi$ that is described by (15). It is also obvious that the duration of the anode $\mathrm{T}_{1}$ and that of cathode $\mathrm{T}_{2}$ half-wave rectified voltage are not the same, moreover $T_{1}=\pi+2 \alpha, \quad T_{2}=\pi-2 \alpha$.

Value of average rectified voltage on $m$-th interval of periodicity:

$$
U_{s}(m)=\frac{2}{\pi} A \cos \alpha+\frac{2}{\pi} B(m) \alpha .
$$

Equation (17) shows that taking into account the unequal duration of each half-wave rectified voltage resulted, at first, in the appearance of the second term in the equation, associated with the aperiodic component of supply voltage. Secondly, the first term in (17) also becomes dependent on the number of considered intervals, because angle $\alpha$ changes from interval to interval, decreasing to zero in the steady mode at fully open thyristors.

From (16) the following equation is written:

$$
\cos \alpha(m)=\sqrt{1-\sin ^{2} \alpha(m)}=\sqrt{1-[B(m) / A]^{2}} .
$$

It can be written taking into account attenuation of the aperiodic component of voltage

$$
\cos \alpha(m)=\sqrt{1-\left(B e^{-\chi 2 \pi(m-1)} / A\right)^{2}} \approx 1-\frac{1}{2}\left(B e^{-\chi 2 \pi(m-1)} / A\right)^{2} .
$$

Equation (16) is also transformed in the following way:

$$
\sin \theta=B e^{-\chi[\theta+2 \pi(m-1)]} / A .
$$

Calculations show that switching of thyristors takes place near the point of their opening in the steady mode near the value $\theta=0$. In this case:

$$
\sin \theta \approx \theta, e^{-\chi[\theta+2 \pi(m-1)]} \approx e^{-\chi 2 \pi(m-1)}+\left.\frac{d}{d \theta} f(\theta)\right|_{\theta=0} ^{* \theta=e^{-\chi 2 \pi(m-1)}(1-\chi \theta) .}
$$

The next step is the change in equation (19) of relevant functions of their approximations by (29)

$$
\alpha=\frac{e^{-\chi 2 \pi(m-1)}}{1+\chi e^{-\chi 2 \pi(m-1)}} .
$$


Therefore, taking into account (18) and (21), we obtain the following law of changes of average rectified voltage for $m$-th range of full repeatability of converter circuit

$$
U_{s}(m)=\frac{2}{\pi}\left[A-\frac{B^{2}}{2 A} e^{-\chi 4 \pi(m-1)}\right]+\frac{2}{\pi} B \frac{e^{-\chi 4 \pi(m-1)}}{1+\chi e^{-\chi 2 \pi(m-1)}} .
$$

We have the following equation after transition from discrete variables (22) to continuous

$$
u_{s}(\theta)=\frac{2}{\pi}\left[A-\frac{B^{2}}{2 A} e^{-\chi 2 \theta}\right]+\frac{2}{\pi} B \frac{e^{-\chi 4 \theta}}{1+\chi e^{-\chi 2 \theta}} .
$$

Discrete variables are used for calculation of transient electromagnetic processes because the obtained finite-difference equations are best suited for their numerical solution. In those cases when electromechanical transition processes are considered, which are accompanied by changes in the speed of synchronous motors, differential equations of continuous variables become more comfortable. In the first case, it is advisable to use (22), and in the second case - (23).

\subsection{Mathematical Model of the Exciter}

Differential equations (7) have a variable structure. Their type and quantity depend on the number of conductive thyristors of converter pre-exciter and exciter. Using LIT allows obtaining equations with permanent structure. Therefore, we use (8) for the third equation of system (7) assuming that $h^{(m)}=\pi / 3, \theta \in\left[\alpha_{0} \alpha_{0}+\pi / 3\right]$. Let us take linear approximation of the current switching $i_{\gamma}^{(m)}(\theta)$ on the integration interval $\theta \in\left[\begin{array}{ll}\alpha_{0} & \alpha_{0}+\gamma\end{array}\right]$. The duration of the intervals $h^{(m)}$ of the constancy of the structure converter $V D 2$ in the transition process and the switching angle $\gamma$ will change. Numerical calculations of transient processes in the electric machine-thyristor motors show [2]-[7] that these factors can be ignored and take their steady-mode values.

The result is

$$
\begin{aligned}
& x_{a d} \frac{\Delta i_{d}^{(m)}}{\pi / 3}+\left[x_{f}+x_{d}^{g}+x_{q}^{g}-\left(x_{d}^{g}-x_{q}^{g}\right) \cos 2 \alpha_{0}\right] \frac{\Delta i_{f}^{(m)}}{\pi / 3}+x_{a d} \frac{\Delta i_{1 d}^{(m)}}{\pi / 3}+\left[\frac{x_{d}^{g}+x_{q}^{g}}{2 \pi / 3}-\frac{r_{g} \gamma}{2 \pi / 3}+\right. \\
& \left.+\frac{\sqrt{3}}{\pi / 3}\left(x_{d}^{g}-x_{q}^{g}\right) \sin \left(2 \alpha_{0}-\pi / 6\right)\right] i_{f l}^{(m)}-\sqrt{3} x_{a d}^{g} \sin \alpha_{0} \frac{\Delta i_{f}^{g(m)}}{\pi / 3}-\frac{\sqrt{3} x_{a d}^{g}}{\pi / 3} \cos \left(\alpha_{0}-\pi / 6\right) i_{f l}^{g(m)}- \\
& -\sqrt{3} x_{a d}^{g} \sin \alpha_{0} \frac{\Delta i_{1 d}^{g(m)}}{\pi / 3}-\frac{\sqrt{3} x_{a d}^{g}}{\pi / 3} \cos \left(\alpha_{0}-\pi / 6\right) i_{1 d l}^{g(m)}+\sqrt{3} x_{a q}^{g} \cos \alpha_{0} \frac{\Delta i_{1 q}^{g(m)}}{\pi / 3}- \\
& -\frac{\sqrt{3} x_{a q}^{g}}{\pi / 3} \sin \left(\alpha_{0}-\pi / 6\right) i_{1 q}^{g(m)}+\left(r_{f}+2 r_{g}\right) i_{f s}^{(m)}=0 .
\end{aligned}
$$


It is acceptable to use $x_{d}^{g} \approx x_{q}^{g}$ for synchronous motors with brushless excitation system. It is possible to ignore the influence of snubber contours with time constant of transient processes also for engines with power several megawatts. As a result, it is possible to reduce (26) to the next taking into account the ratios of the parameters:

$$
\begin{aligned}
& x_{a d} \frac{\Delta i_{d}^{(m)}}{\pi / 3}+x_{f} \frac{\Delta i_{f}^{(m)}}{\pi / 3}+\frac{x_{d}^{g}}{\pi / 3} i_{f l}^{(m)}-\sqrt{3} x_{a d}^{g} \sin \alpha_{0} \frac{\Delta i_{f}^{g(m)}}{\pi / 3}- \\
& -\frac{\sqrt{3} x_{a d}^{g}}{\pi / 3} \cos \left(\alpha_{0}-\pi / 6\right) i_{f l}^{g(m)}+\left(r_{f}+2 r_{g}\right) i_{f s}^{(m)}=0 .
\end{aligned}
$$

Equation (25) cannot be attributed either to finite-difference equations, because it contains the average value of the variable $i_{f_{s}}^{(m)}$, or to the equations in jaggies [11], because it contains samples of variables $i_{f l}^{(m)}$ and $i_{f l}^{g(m)}$. Therefore, (25) is necessary to lead to the first or another type. The value of (25) is in permanent structure and it does not depend on the switching thyristor inside the discretization interval. As excitation currents of pre-exciter and exciter, accordingly $i_{f l}^{(m)}$ and $i_{f l}^{g(m)}$, are smoothed by large inductance of the windings, let us assume that, $i_{f l}^{(m)} \approx i_{f s}^{(m)}$ and $i_{f l}^{g(m)} \approx i_{f s}^{g(m)}$. Then, according to [11], the resulting equation in the jaggies will correspond to the following equivalent differential equation in the continuous variables

$$
x_{a d} \frac{d i_{d}}{d \theta}+x_{f} \frac{d i_{f}}{d \theta}-\sqrt{3} x_{a d}^{g} \sin \alpha_{0} \frac{d i_{f}^{g}}{d \theta_{c}}-\frac{\sqrt{3} x_{a d}^{g}}{\pi / 3} \cos \left(\alpha_{0}-\pi / 6\right) i_{f}^{g}+\left(r_{f}+2 r_{g}+\frac{x_{d}^{g}}{\pi / 3}\right) i_{f}=0 .
$$

Active resistance compared with inductive resistance of rotor of pre-exciter can be ignored in the last term of (28), if only active resistance in the rotor circuit is not entered to decrease the field.

Differential equation of pre-exciter needs to be added for obtained equations. It looks like written relatively discrete variables

$$
U_{f s}^{g(m)}=r_{f}^{g} i_{f_{s}}^{g(m)}-\frac{2 \sqrt{3}}{\pi} x_{a d}^{g} \sin \alpha \Delta i_{f}^{(m)}+x_{f}^{g} \frac{\Delta i_{f}^{g(m)}}{\pi / 3} .
$$

The equivalent differential equation correspondence:

$$
u_{f}^{g}=r_{f}^{g} i_{f}^{g}-\frac{2 \sqrt{3}}{3} x_{a d}^{g} \sin \alpha \frac{d i_{f}}{d \theta}+x_{f}^{g} \frac{d i_{f}^{g}}{d \theta} .
$$

Equation (28) should be used simultaneously with (23) because $u_{f}^{g}=u_{s}(\theta)$ 


\section{RESULTS AND DISCUSSION}

Usually switchgear section of power plants and substations of 110-220 kV are electrically connected through sectional switches. In these cases, short circuits spread in grids of $110-220 \mathrm{kV}$ as voltage dips and for low voltage levels of connected substations. As a result, automatic reserve switching becomes ineffective and exciters of synchronous machines work at low voltage. The law of this change is determined by the parameters of the external power supply system.

The resulting mathematical model of brushless excitation system, containing two thyristor converters, allows performing calculations of verification of working modes of SM under conditions of influence of short-term power outages on the system of excitation through the supply grids.

Voltage dips with rectangular shape cause simultaneous reduction of excitation current of pre-exciter and SM. Aperiodic character of the voltage changes at short-term power may cause short rise of the excitation current of pre-exciter.

The laws of change excitation current of synchronous motors on the initial parts depend on shape of the curve voltage dip: the aperiodic law of changes in supply voltage causes the growth of the excitation current at the beginning of the transitional process.

Discrete mathematical model permanent structure of excitation system of SM adequately reproduces electromagnetic transient processes that allow using it for return to continuous variables. Switching current $i_{\gamma}$ can be approximated in linear form during its integrating. It requires individual research for distribution of discrete models in electromechanical transient process, because changing of the rotational speed of SM is determined by changes in the electromagnetic moment, which cannot be converted mathematically rigorous to step images or finite difference sight. Having carried out a pre-removal switching of thyristors taking into consideration the method proposed above, it is recommended to remain in the framework of mathematical model in continuous variables.

\section{CONCLUSIONS}

A special feature of mathematical modelling of a synchronous machine with a brushless excitation system is needed for adequate mapping simultaneous operation of two converters, causing the variable structure of differential equations. This problem allows removing transition to equivalent equations. Intermediate transition from discrete variables to local image for each inverter followed by a return to differential equations with permanent structure provides a mathematical description of the synchronous motor operation with respect to "useful" components in the currents of excitation.

Short circuits in the external power supply system lead to voltage dips in both sections of low voltage in industrial substations, which makes inefficient the system of reservation power of excitation windings of synchronous machine exciter from adjacent sections of switchgears of the systems of internal power supply.

Perhaps the mathematical description of electromagnetic transients in syn- 
chronous machines is appropriate in the form of finite-difference equations. The speed of calculations is repeatedly increased and conditions are created for the development of automatic systems of control and protection, using "the projected" development mode under external distortion. It is reasonable to use the mathematical model of a permanent structure in the continuous variables for the description of electromechanical transient process.

\section{REFERENCES}

1. Abdullazyanov, E.Y. (2009). Limiting the Impact of Short-Term Power Failure at Industrial Consumers. Scientific publication. Publishing House of KSPEU.

2. Kuznetsov, V.A., and Fedotov, A.I. (1999). Using the local Fourier transform for the mathematical modeling of synchronous machines with brushless excitation systems. Electricity. No. 4, 13-22.

3. Kryuchkov, I.P., Starshinov, V.A., and Gusev, Y.P. et al. (2008). Transients in Electric Power Systems. Moscow: Publishing House MEI.

4. Beregovenko, G.Y., Pukhov, G.E., and Saukh, S.E. (1993). Numerical Methods for Solving Differential Operator Equations and Analysis of Dynamical Systems. Kiev: Science. Dumka.

5. Zhenya, L. (2015). Ultra-High Voltage AC/DC Grids. Academic Press.

6. Huadong, S., Yong, T., and Shiying, M. (2006). A commentary on definition and classification of power system stability. Power Syst. Technol. 30(17), 31-35.

7. Xiaojiang, G., Yong, T., Qiang, G. et al. (2012). Influence factors and theory for CIGRE MSCR index. Power Syst. Prot. Control. 40(9), 69-74.

8. Xiaojiang, G., Jianbo, G., Shiying, M. et al. (2013). A method for multi DC terminal location selection based on multi-infeed short circuit ratio. Proc. CSEE. 33(10), 36-42.

9. Rongjiang, C., Nihong, G., and Yong, S. (1996). Test study on self-extinction behavior of secondary arc on power system. Proc. CSEE. 16(2), 73-78.

10. Curatolo T, and Cogger S. (2005). Enhancing a power supply to ensure EMI compliance. EDN. 50(2), 67-74.

\section{SPRIEGUMA IETEKME UZ SINHRONO MAŠĪNU AR BEZSUKU IEROSMES SISTĒMU}

Fedotovs A., Leonovs A. Vagapovs G., Mutule A.

Kopsavilkums

Rakstā piedāvāts matemātiskais modelis ar nepārtraukti mainīgajiem lielumiem sinhronai mašīnai ar bezsuku ierosmes sistēmu, saturošu tiristora elementu. Laplasa diskrētā transformācija tiek izmantota pārejai no vienādojumiem maināmai struktūrai ar nepārtraukti mainīgu lielumu matemātisko modeli uz galīgu diferenču vienādojumiem pastāvīgām struktūrām. Pēc tam veikta apgrieztā pāreja uz matemātisko modeli ar nepārtraukti mainīgiem lielumiem pastāvīgai struktūrai.

25.02.2016. 